\title{
Sciendo
}

Administration, vol. 68, no. 1 (2020), pp. 39-48

doi: 10.2478/admin-2020-0004

\section{Health services, 2019}

\author{
Fiona Keogh \\ Centre for Economic and Social Research on Dementia, NUI Galway, \\ Ireland
}

\section{The National Paediatric Hospital}

The year began with a focus on the increasing expenditure on the National Paediatric Hospital (NPH). The NPH is the largest capital investment programme ever undertaken in Ireland's healthcare system. It comprises the New Children's Hospital (NCH) at St James's Hospital as well as outpatient and urgent care centres located at Connolly and Tallaght Hospitals. Members of the National Paediatric Hospital Development Board (NPHDB) were appointed in 2013, and in 2014 the Department of Health approved a total budget of $€ 790$ million for the NPH Project. A final total cost of $€ 983$ million to cover the construction and equipping of the $\mathrm{NCH}$ and the two satellite centres was agreed in April 2017.

By December 2018 the estimated cost of building the $\mathrm{NCH}$ and satellite centres had increased by $€ 450$ million to $€ 1.43$ billion. To complete the hospital, it is estimated that a further $€ 293$ million will be required for other items, including IT systems and implementation of an electronic health record system. Including a provision of $€ 40$ million for costs already incurred in relation to the Mater Hospital site, the current estimated cost of the NPH Project is $€ 1.73$ billion.

In January the chair and members of the NPHDB and officials from the Department of Health were invited to the Oireachtas Health Committee to address the increased spending on the project. As well as concerns on the scale of the escalating costs, concerns were raised 
with regard to the potential impact of the cost overrun on all capital investment in health in the coming years. The Health Committee met with the Minister for Health, Simon Harris, TD, and the secretary general for the Department of Health, Jim Breslin, to examine these issues and the future financial controls for the project.

PwC was commissioned in January by the HSE, on behalf of government, to conduct an independent review to understand the reasons for the cost escalation of the NPH construction project. The review, published in April, concluded that:

Significant failures occurred during the crucial planning and budgeting stages of the project. The basis of the original budget was flawed and risks were understated in the business case. There was a lack of sufficiently comprehensive or robust planning for the process to establish a Guaranteed Maximum Price (GMP) for the construction of the New Children's Hospital. This created a situation in which the approved project could never be delivered within the financial parameters agreed. (PwC, 2019, p. 4)

In terms of execution and governance, the review concluded that the process to determine the GMP was 'poorly coordinated and controlled' and that 'the level of trust that the NPHDB placed on the NPH Executive and Design Team gave rise to insufficient scepticism and challenge' (PwC, 2019, p. 5). The review report made eleven recommendations, nine relating to the NPH itself and two relating to capital infrastructure projects generally, on how the rules, assurance and challenge functions within government could be strengthened.

The Public Accounts Committee (PAC) met with the NPHDB twice in 2019, in January and May, to consider the tendering process for the project and the escalating costs. The July 2019 periodic report of the PAC recommended that the two-phase tender process employed in the NPH project is not used in the future for major capital projects unless both phases are fully designed in advance, and that all the recommendations of the $\mathrm{PwC}$ review be implemented without delay (Committee of Public Accounts, 2019). The PAC report, published in July, concluded that the Department of Health, as the sponsoring department of the NPH Project, had not provided proper oversight or ensured coherence on all aspects of the project. 


\section{Industrial relations}

A number of industrial relations issues affected health services throughout 2019. A national strike of members of the Irish Nurses and Midwives Organisation (INMO) took place on 30 January in a dispute relating to the recruitment and retention of nurses and midwives on current salary levels and safe staffing in the health service. Talks between the INMO, the Health Service Executive (HSE) and the Department of Health at the Workplace Relations Commission failed to reach a resolution and further strikes were held on 5 and 7 February, leading to the cancellation of over 50,000 appointments and procedures. Following the formal intervention of the Labour Court, further strikes were cancelled. A new contract for nurses was negotiated, which focused on supporting the implementation of the Sláintecare programme and also addressed some of the concerns underlying the dispute through an 'Enhanced Nurse Practice' salary scale and improved allowances. Members of the INMO voted in May to accept the Labour Court proposals and the dispute was resolved.

In June healthcare workers, including healthcare assistants, maternity care assistants, porters, laboratory aides, chefs and surgical instrument technicians, held a one-day strike as part of a dispute over the failure of the HSE to implement the findings of a job evaluation scheme. Further strike action was deferred following the intervention of the Labour Court. In September healthcare workers voted in favour of the Labour Court recommendations. Members of the National Ambulance Service Representative Association (NASRA), which is a branch of the Psychiatric Nurses Association (PNA), staged a series of strikes in 2019 as part of a campaign to secure representation rights. The HSE does not recognise the PNA or its NASRA branch as a representative body for ambulance personnel. This dispute is ongoing.

In terms of industrial relations, 2019 ended with a vote by consultant and non-consultant members of the Irish Medical Organisation to take strike action in the absence of a resolution to the current dispute over pay and recruitment issues. There had been calls throughout 2019, and in previous years, for an end to the 'twotier' pay system, which means medical specialists appointed after October 2012 are paid less than consultants who were in their posts before then. 


\section{HSE governance}

Eight new appointees to the board of the HSE were announced in January to join Ciarán Devane, announced as chair of the HSE board in September 2018. The new appointees were: Fergus Finlay, Tim Hynes, Prof. Deirdre Madden, Dr Sarah McLoughlin, Mark Molloy, Aogán Ó Fearghail, Fiona Ross and Dr Yvonne Traynor. Two additional board members were announced in May: Brendan Lenihan and Prof. Fergus O'Kelly. A range of skills and competencies are represented on the board. The Health Service Executive (Governance) Bill, 2018, to amend the Health Act, 2004, was signed into law in June 2019. Under this bill, the board will be the governing body of the HSE and will be accountable to the Minister for Health for the performance of its functions. The director general of the HSE will be accountable to the board. Paul Reid was appointed as director general of the HSE in April, replacing Tony O'Brien, who resigned as CEO of the HSE in May 2018.

A major restructuring of the HSE was announced in July. Six regional health areas will be formed, based on population data, including how people currently access health services. Public consultation also informed the configuration of the new regional areas. These regional health bodies will have their own budget based on local population needs and will be responsible for the planning and delivery of integrated health and social care services. The new regional health areas are in line with recommendations made in the 2017 Oireachtas Committee on the Future of Healthcare Sláintecare Report and represent a further step towards the implementation of Sláintecare.

\section{Sláintecare}

Work on the implementation of Sláintecare continued with the publication of the Sláintecare Action Plan 2019 in June. The plan outlines the project management structures and governance approach for the ten-year implementation of Sláintecare and the actions and milestones for 2019. Applications to the Sláintecare Integration Fund were invited to identify and support work which is aligned with the goals of Sláintecare. Over 477 projects applied to the fund and 122 projects from across the country were successful. The successful projects aim to: demonstrate innovative ways in which citizens can engage in their own health; represent best practice in the management 
of chronic diseases and caring for older people; and encourage innovations in the shift of care to the community or promote hospital avoidance. Specific elements of the budget announcements for the health sector in 2019 were aimed at building up community-based services, as recommended in Sláintecare, namely: the provision of $€ 60$ million to recruit 1,000 frontline staff into the community by the end of 2021; €45 million to support the expansion of free GP care to children under eight and free dental care for children under six; an additional 1 million home help hours and the roll-out of a pilot statutory home care scheme. In December a new Sláintecare consultant contract was announced. From Q2 2020, all consultant appointments will be made under this new contract, which requires consultants employed by the state to focus 100 per cent of their time on public-only work.

\section{CervicalCheck}

The fallout from the CervicalCheck scandal continued throughout 2019. Following the publication in September 2018 of the Final Report of the Scoping Inquiry into the CervicalCheck Screening Programme (the Scally report), Dr Scally committed to providing a supplementary report into certain aspects of the laboratories involved in the screening process, such as procurement, quality and accreditation arrangements, and governance structures. This supplementary report was published in June and revealed several concerns. Firstly, the number of laboratories involved in CervicalCheck work was sixteen (two in Ireland, two in the UK, and twelve in the US). This is a significant increase on the six laboratories that were understood to be involved at the outset of the work on the Scoping Inquiry, and the total of eleven which was reported in the final Scally report. Secondly, the use of many of these laboratories for CervicalCheck screening was not approved in advance by the HSE/National Screening Service, nor was their use known to the HSE/National Screening Service. Thirdly, a laboratory used for CervicalCheck screening in Greater Manchester was retrospectively accredited for periods of time during which its existence was unknown to the Irish National Accreditation Board. However, in the supplementary report, Dr Scally concluded that laboratory services used in the past, or those currently used, have provided, or are providing, a service which meets acceptable standards in their country of operation, and that 'despite the number of laboratories in use at various times, the Inquiry team did not, in the 
course of its work, uncover any evidence to suggest deficiencies in screening quality at any laboratory' (Scally, 2019, p. iii).

An implementation plan to address the recommendations of the Scally report was published by the Department of Health at the end of 2018 and is required to be regularly and independently reviewed. The first Implementation Progress Report was published in February and noted substantial progress being made across the different agencies involved with a significant commitment of resources. In June a CervicalCheck Steering Committee was established by Minister Harris to provide oversight and assurance on the implementation of key decisions taken by government in relation to CervicalCheck. The steering committee included three patient representatives.

However, further controversy emerged towards the end of the year with the publication of the report of the Royal College of Obstetricians \& Gynaecologists (RCOG) Independent Expert Panel Review (2019) in December. The purpose of the review was to provide women who participated in the national CervicalCheck screening programme and who developed invasive cervical cancer with independent clinical assurance about the timing of their diagnosis and treatment. The slides of 1,038 women were reviewed. The review disagreed with the CervicalCheck result in 308/1034 (29.8 per cent) cancer cases. In 159/308 (51.6 per cent) of these discordant cases, the expert panel considered that the CervicalCheck result had an adverse effect on the woman's outcome. That is to say, had the abnormalities found on review been recognised at the time, this might have provided an opportunity to prevent cancer or to detect cancer at an earlier stage in 159 cases. Prof Henry Kitchener, lead assessor for the RCOG, noted that the 30 per cent discordance rate found by the CervicalCheck review is similar to that found in a much larger review of cases in England. Overall, the report concluded that the Irish screening programme is performing effectively. Ten recommendations were made, which were accepted by government.

Following the publication of the RCOG review, an editorial in The Irish Times commented on two limitations of the review: reviewers were not blinded - that is, those reassessing the slides knew they represented proven cancer cases; and one-third of eligible women declined to participate in the slide review ('Irish Times view', 2019). A number of errors also arose in the course of the review with mislabelled slides. A small number of women were told one set of results only to be later told a different result. This undermined 
confidence in the review process. One of the patient representatives on the CervicalCheck Steering Committee raised concerns about the RCOG review and reported that her concerns were not taken seriously, describing her experience of the steering committee as 'horrendous'. She resigned from this committee in early December following the publication of the RCOG review report.

\section{Home care}

The home support service (formerly the home care service) was the subject of much discussion in 2019. Concerns over waiting times and lack of availability of home support hours led to parliamentary questions and media commentary. In May Minister Jim Daly, TD, released a statement on improving access to home support. The minister acknowledged that in spite of an increased budget for home support, demand continues to grow and outstrip supply, leading to significant waiting lists in some areas of the country. The minister also acknowledged the considerable variation in access to services in different parts of the country. The Department of Health is developing a new stand-alone, statutory scheme for the financing and regulation of home support services, which is a key action under the Sláintecare Implementation Strategy. The HSE National Service Plan 2020 commits to the provision of 1 million additional home support hours, which includes 230,000 hours of home support to be provided in conjunction with the roll-out of a pilot home support scheme.

A related development was the announcement in November of the Community and Voluntary Supports Grant Scheme, a joint initiative of Minister Daly and the HSE. This scheme provides an extra $€ 1$ million funding to community and voluntary groups to continue to support older people, family carers and significant others to stay well and remain connected with their local community.

\section{Report of the review of the voluntary sector}

In February the report was published of an Independent Review Group (2019) established to examine the role of voluntary organisations in the provision of health and personal social services. In the context of the proposed reconfiguration of health services envisaged in Sláintecare, an important part of the terms of reference of the review was to make recommendations to the Minister for Health on the principles which should inform the future relationship 
between the state and voluntary service providers. A key finding of the report is that Ireland benefits from having a voluntary sector and that it should continue to play an integral role in the delivery of health and social care services. The review group found a high level of mutual interdependence between the state and voluntary organisations and emphasised the complex, intertwined and evolving relationship that has existed between the two sectors for many years. The group called for a renewal of this relationship based on trust and partnership, and noted the necessity to put the ongoing relationship between the state and the voluntary sector on a clearly defined basis for the future. Twenty-four recommendations were made, covering areas such as the governance of voluntary organisations; dialogue, reporting and contractual processes between the state and the voluntary sector; ethos, asset ownership and public capital investment; and broader issues related to health system development.

\section{Housing for older people}

The publication in February of a joint policy statement between the Department of Health and the Department of Housing, Planning and Local Government (2019), entitled Housing Options for our Ageing Population, represented an important initiative in terms of crossdepartmental working. The joint statement provides a policy framework to create a much wider spectrum of housing options and choices for older people in Ireland. This is in line with long-standing policy in Ireland to support people to grow old and live in a community of their choosing, with dignity and independence. There are forty action points in the plan, underpinned by six principles: ageing in place; supporting urban renewal; promoting sustainable lifetime housing; using assistive technology; staying socially connected; and working together. An Interdepartmental/agency Implementation Group with an independent chair has been established to progress the delivery of actions.

\section{Reforming research ethics committees}

Of particular relevance to all those involved in health research was the publication in July of the General Scheme of the National Research Ethics Committees Bill. Concerns have been raised for some time by the Health Research Board and others about the existing Research 
Ethics Committee system in Ireland for clinical trials and health research generally. There was a recognition that a more streamlined, regulated and fit-for-purpose model for the ethical review of health research projects was required. The bill enables the establishment of a number of national research ethics committees, to be supported by dedicated staff in a National Office for Research Ethics Committees (to be hosted by the Health Research Board).

A related development was the appointment of fifteen people to the Health Research Consent Declaration Committee (HRCDC) in March. The HRCDC was provided for in the Health Research Regulations made by Minister Harris under the Data Protection Act, 2018. The committee has a decision-making role in those limited situations where it is not possible to obtain the consent of an individual for the obtaining and use of personal information and where the public interest of doing the research significantly outweighs the need for explicit consent. In these situations, a data controller carrying out health research using personal data can apply for a consent declaration, which means that the consent of the individual is not required. As an independent and representative committee, the HRCDC makes decisions on those applications.

\section{Topical issues}

Finally, while Brexit and climate change are covered in detail in reviews of other sectors, these issues also featured in the health sector. As part of the whole-of-government response to Brexit, the Department of Health is working to ensure a comprehensive and coordinated set of preparations to ensure continuity of health services post-Brexit. The Health and Childcare Support (Miscellaneous Provisions) Bill, 2019, was signed into law in October. This bill addresses key health issues in the context of the exit of the UK from the EU, namely the provision of health benefits similar to those under the European Health Insurance Card to eligible residents of Northern Ireland, and an amendment to the Childcare Support Act, 2018, to make explicit provision for British citizens to access the National Childcare Scheme on the same basis as Irish citizens.

The first Climate Change Adaptation Plan for the Health Sector 2019-2024 was published in October (Department of Health, 2019). The plan was developed by a joint department-HSE team of officials and doctors following a public consultation, and identifies six main 
climate scenarios with the most profound health implications. Two of the six scenarios relate to slow-onset climate effects over time (UV radiation and air pollution) and four scenarios concern acute, severe weather events (windstorms, extreme heat and heatwaves, high precipitation and flooding, and extreme cold snaps). A Climate Change Oversight Group will be established for the health sector, whose role will be to drive and oversee implementation of the plan.

\section{References}

Committee of Public Accounts. (2019). Periodic report no. 6 selected matters October 2018 - May 2019. Dublin: Houses of the Oireachtas.

Department of Health. (2019). Climate change adaptation plan for the health sector 2019-2024. Dublin: The Stationery Office.

Department of Health and the Department of Housing, Planning and Local Government. (2019). Housing options for our ageing population. Policy statement. Dublin: The Stationery Office.

Independent Review Group. (2019). Report of the Independent Review Group established to examine the role of voluntary organisations in publicly funded health and personal social services. Dublin: The Stationery Office.

PwC. (2019). New Children's Hospital: Independent review of escalation in costs. Retrieved from https://merrionstreet.ie/MerrionStreet/en/News-Room/ Releases/20190409_NCH_Report.pdf [7 January 2020].

RCOG Independent Expert Panel Review. (2019). Cervical screening in cases of cervical cancer in Ireland between 2008 - 2018. London: RCOG.

Scally, G. (2019). Scoping Inquiry into the CervicalCheck Screening Programme. Supplementary report. Retrieved from https://www.gov.ie/en/pressrelease/ac259b-minister-harris-publishes-the-supplementary-report-ofthe-scoping-in/? referrer=/blog/publications/scoping-inquirysupplementary-report/ [7 January 2020].

The Irish Times view on CervicalCheck: A verdict on the screening system [Editorial]. (2019, 4 December). Retrieved from https://www.irish times.com/opinion/editorial/the-irish-times-view-on-cervicalcheck-averdict-on-the-screening-system-1.4104867 [7 January 2020]. 